\title{
Comparison of community based smoke detector distribution methods in an urban community
}

\author{
Malinda Reddish Douglas, Sue Mallonee, Gregory R Istre
}

\begin{abstract}
Objectives-Various methods of soliciting participation for a large smoke detector giveaway program were tested to determine the most effective method of distributing smoke detectors to a high risk urban population.

Setting-The target area was a 24 square mile $\left(62 \mathrm{~km}^{2}\right)$ section on the south side of Oklahoma City where $16 \%$ (73 301) of the city's population resided in $16 \%(34845)$ of the dwellings (excluding apartments). Of the 66 persons in Oklahoma City who were injured in residential fires from September 1987 to April 1990, 45\% (30) were in the target area. Of the target area injuries, $47 \%$ resulted from fires started by children playing with fire (fireplay).
\end{abstract}

Methods-The number of homes without detectors was estimated by telephone survey. Four different methods of soliciting participants were used, including notifying residents by mail; placing flyers on the doors of every habitable residence; and displaying flyers at public places (grocery stores, convenience stores, restaurants, etc). Each of these methods alerted residents that free smoke detectors were available at specific fire stations. The fourth method was distributing detectors door-to-door (canvassing).

Results-The canvassing method resulted in significantly more smoke detectors being distributed to homes without detectors $(107 \%)$ than any of the three other methods $(18 \%)(p<0.00001)$. The canvassing method distributed detectors to $31 \%$ of the total target homes, compared with $5 \%$ with the other methods ( $p<0.00001)$. Canvassing also resulted in the lowest estimated cost per detector distributed (\$1.96) (all other methods, \$3.95), and in the largest number distributed per volunteer hour (5.9 $v 3.1$ detectors per hour by other methods).

Conclusions-Distributing smoke detectors directly to homes (canvassing) was the most effective and cost efficient method to reach high risk urban residents.

(Injury Prevention 1998;4:28-32)

Keywords: house fires; smoke inhalation; smoke detectors

Prevention Center and Pediatric Critical Care Associates, Dallas, Texas, USA

G I Istre

Correspondence and reprint requests to: Malinda Reddish Douglas, Injury Prevention Service - 0307, Oklahoma State Department of Health, 1000 NE 10th Street,

Oklahoma City, OK

73117-1299, USA. industrialized nation outside the former Soviet bloc. ${ }^{1}$ In 1991, the US rate (17.7) was $20-33 \%$ higher on average than Japan (14.7), Canada
From 1977 to 1991 , the US civilian fire death rates have declined from 34.4 deaths per million population to $17.7 .{ }^{1}$ However, the US has the highest fire death rate of any other
(14.2), the UK (14.2), and Sweden (13.3). ${ }^{1-4}$ Residential fires account for an estimated $70 \%$ to $75 \%$ of the fire related deaths ${ }^{5}$ and $66 \%$ of all fire related injuries in the US. ${ }^{5}$ About one out of every 16 to 17 homes will experience a residential fire. ${ }^{7}$ Each year in the US an estimated 5000 persons die and an additional 30000 persons are hospitalized due to residential fires. ${ }^{8}$ Carbon monoxide intoxication or smoke inhalation causes the majority of these deaths, ${ }^{6-11}$ while burns are the cause of injury among the majority of persons who survive these fires. ${ }^{12} 13$

From 1987 to 1990, Oklahoma City had the highest annual rate of residential fire related injury (5.6/100 000 population) in Oklahoma; a small contiguous area on the city's south side (target area) with $16 \%$ of the population accounted for $45 \%$ of the injuries. The target area injury rate was more than four times higher than that of the rest of the city (15.3 and 3.6 per 100000 , respectively). ${ }^{14}$ Surveillance data indicated that in the target area $47 \%$ of the residential fire related injuries resulted from children playing with fire (fireplay), followed by cigarettes $(17 \%)$, flammable liquids $(13 \%)$, heating devices $(10 \%)$, and other or unknown causes $(13 \%)$. This pattern differed considerably from the rest of the city, where residential fire related injuries were most often caused by heating devices (42\%); this was followed by cooking (14\%), cigarettes $(11 \%)$, fireplay $(8 \%)$, electrical systems $(6 \%)$, flammable liquids $(6 \%)$, and other or unknown causes $(14 \%)$. The demographic characteristics of the target area showed a higher proportion of Hispanic, Native American, and other non-black minority populations, lower median household income, lower property and rental value, as well as lower quality of housing as compared with the rest of Oklahoma City. According to Oklahoma City Fire Department data, homes having fires in the target area were less likely to have a smoke detector $(23 \%)$ than homes having fires in the rest of Oklahoma City (40\%) (unpublished data).

A large smoke detector giveaway was implemented in south Oklahoma City in May, 1990. During the four years after the program, there was an $80 \%$ reduction of residential fire related injuries in the target area while the rest of the city experienced a $7 \%$ increase in these injuries. ${ }^{14}$ The target area experienced a $25 \%$ decline in the annual rate of reported fires per 1000 homes (6.4 to 4.8) after the program. The rest of the city experienced a similar but smaller decline in fire incidence rate $(18 \%, 3.9$ to 3.2$).{ }^{14}$ Additionally, the injury rate per 100 residential fires decreased $74 \%$ in the target 
Table 1 Distribution of smoke detectors to total homes and to those without detectors homes by methods, Oklahoma City, May 1990

\begin{tabular}{|c|c|c|c|c|c|c|c|c|}
\hline \multirow[b]{2}{*}{$\begin{array}{l}\text { Zip code } \\
\text { postal } \\
\text { area }\end{array}$} & \multirow[b]{2}{*}{$\begin{array}{l}\text { Total } \\
\text { homes }\end{array}$} & \multirow[b]{2}{*}{$\begin{array}{l}\text { Participant solicitation/distribution } \\
\text { method }\end{array}$} & \multirow[b]{2}{*}{$\begin{array}{l}\text { Detector } \\
\text { prevalence }\end{array}$} & \multirow[b]{2}{*}{$\begin{array}{l}\text { Estimated } \\
\text { homes } \\
\text { without } \\
\text { detectors }\end{array}$} & \multirow[b]{2}{*}{$\begin{array}{l}\text { No of } \\
\text { homes } \\
\text { receiving } \\
\text { detectors }\end{array}$} & \multicolumn{3}{|c|}{ Distributed (\%) } \\
\hline & & & & & & $\begin{array}{l}\text { Total } \\
\text { homes }\end{array}$ & $\begin{array}{l}\text { Homes } \\
\text { without } \\
\text { detectors }\end{array}$ & $\begin{array}{l}\text { Cost } \neq / \text { detector } \\
\text { distributed }\end{array}$ \\
\hline 73108 & 6182 & Canvass/door to door & 71 & 1793 & 1925 & 31 & 107 & $\$ 1.96$ \\
\hline 73109 & 9171 & Flyers in public places/fire stations & 70 & 2751 & 278 & 3 & 10 & $\$ 5.38$ \\
\hline 73119 & 11525 & Flyers mailed/fire stations & 74 & 2996 & 751 & 6 & 25 & $\$ 3.40$ \\
\hline 73129 & 8067 & Flyers placed on doors/fire stations & 70 & 2420 & 479 & 6 & 20 & $\$ 3.98$ \\
\hline
\end{tabular}

^Random telephone survey, February 1990.

tTotal homes $\times(1$-prevalence in the telephone survey).

$\ddagger$ Utilizing cost estimates for labor, equipment, and participant solicitation.

area while in the rest of the city the rate increased $32 \%$ from 1.9 to $2.5 .^{14}$ Three months after the initiation of the smoke detector giveaway program, $65 \%$ of the detectors surveyed in a random sample survey of households receiving them through the program were installed and functional. ${ }^{14}$

Although injury prevention theory suggests that it is likely that the one time action of installing a smoke detector will be taken, ${ }^{15}$ little data exist with regard to the most effective ways to conduct smoke detector distribution programs. ${ }^{15-17}$ This study describes the evaluation of four different methods to solicit resident participation as well as two methods to distribute smoke detectors during this intervention.

\section{Methods}

According to the 1990 US census, Oklahoma City had a population of 444719 residing in 213607 dwellings. The target area consisted of four postal zip code areas containing $16 \%$ (73 301) of the population of the city in $16 \%$ (34 945) of the city's dwellings (table 1). Population demographics and socioeconomic factors were similar among the postal zip code areas within the target area. Renters and home owners without functioning smoke detectors were eligible for the program. Because apartment owners are required by ordinance to provide detectors in each unit, apartment complexes were not targeted for participation; apartment renters, however, were not excluded from the program.

To determine the prevalence of smoke detectors in each zip code area, a random telephone survey of target area residents was conducted three months before implementation. Procedures for the survey were similar to the Behavioral Risk Factor Surveillance System. ${ }^{18}$ To estimate the number of homes in need of a smoke detector, we applied the product of one minus the prevalence of households self reporting functional smoke detectors from the telephone survey to the number of occupied single or multiple family dwellings (excluding apartments) identified in the 1990 census. The survey was completed by $68 \%$ of 1435 randomly selected telephone numbers. Of the remaining telephone numbers, $15 \%$ refused participation or quit mid-survey, $15 \%$ were no answers/non-working, and $2 \%$ were businesses. According to the telephone survey, $72 \%$ of the homes in the target area reported a functioning smoke detector (range $70-74 \%$ ) for the four zip code areas.
PROGRAM

Newspapers, television and radio stations, and churches in the target area were notified about the injury problem and impending detector distribution. In-person conferences were held with each principal from the 16 elementary schools (grades kindergarten through fourth) from the target areas. Information on the upcoming smoke detector giveaway, and the leading causes of residential fire related injury, was shared with the principals who gave permission for the program to enter their schools. Each school participated in distributing to parents special information about the smoke detector giveaway, and each child received educational material illustrating fire hazards and escapes. Information and materials were distributed to 5932 children through the elementary schools.

Free smoke detector installation was offered to every participant by Kiwanis clubs, Boy Scouts of America groups, and fire department personnel. Applications, including demographic information (name, address, and number of persons handicapped, under 5 years of age, over 65 years of age in the household) and program information (including how the participant learned of the program and installation method) were completed for each participant. Detector installation and maintenance instructions, and educational material describing the causes and prevention of house fires (fireplay, smoking, flammable liquids, heating equipment, etc), emergency notification (911), and escape plans, were given to each participant. Educational material emphasized the magnitude and prevention of fireplay related fires. All detector applications and educational materials were prepared in English and Spanish.

In May 1990, residents were specifically notified (participant solicitation) by four different methods and smoke detectors were distributed by two methods (table 1). Flyers notifying residents of the injury problem and the prevention program, including places, dates, and times of the "smoke alarm giveaways" were distributed (by mail, door-to-door, or in public places) in three zip code areas; in each of these, residents were required to go to one of the seven neighborhood fire stations where volunteers were available to distribute smoke detectors on 21 days during the month. Flyers were distributed (door-to-door) by local boy scouts and other volunteers. Additionally, signs announcing the availability of free smoke detec- 
tors were displayed at participating fire stations on designated distribution days.

In the fourth zip code area, an Oklahoma City Fire Department engine or ladder truck traveled down each street, intermittently sounding its siren and announcing the "giveaway" over a loud speaker (canvassing); the vehicle additionally had banners hanging on both sides advertising "free smoke alarms". The fire service vehicles were out of service and served to draw the children and adults out of their homes. Eight volunteers walked behind the truck and distributed smoke detectors to households without one. Another volunteer drove an Oklahoma County Chapter of the American Red Cross marked vehicle that provided transportation for the volunteers and supplies. In each session, the nine volunteers canvassed approximately 500 homes in a three hour period. Canvass routes were not preannounced nor were flyers used.

Smoke detector recipients signed a release of liability in case of subsequent fire or injury, and an agreement to allow program representatives to check the installation and functional status of the detector at a later date. Every recipient also received verbal instructions on the installation and maintenance of the detector, as well as a demonstration of how to change the battery and test the detector. Batteries were distributed to homes that had detectors but were in need of a battery.

Approximately 450 volunteers from over 30 private, civic, and government organizations and agencies volunteered for the program. The canvassing method used 81 volunteers for nine canvass sessions, for a total of 342 volunteer hours accumulated; the fire stations used 168 volunteers to maintain 21 distribution dates totaling 504 volunteer hours.

\section{EVALUATION METHOD}

To analyze which participant solicitation and distribution method was most effective (how well the program worked to produce a desired effect), we compared the number of detectors distributed in each area to the total number of homes and to the estimated number of homes in need of a smoke detector.

The efficiency (how well resources were used) of the distribution methods was determined by calculating the number of detectors distributed per volunteer hour. Cost efficiency of each method was evaluated by adding the cost of participant solicitation (that is, methods of flyer distribution or use of fire department vehicles) to the estimated cost of using paid personnel to distribute the smoke detectors. Costs for paid personnel were estimated using a rate of $\$ 7.00$ per volunteer hour worked distributing smoke detectors and $\$ 5.00$ per volunteer hour for flyer distribution; actual cost was used for mailing flyers. Informational materials, smoke detectors, and battery costs were not included in the estimates.

STATISTICAL ANALYSIS

Standard statistical analysis of distribution methods and installation preference were performed using Epi-Info, version 6 software package. ${ }^{1920}$

\section{Results}

A total of 3564 smoke detectors were distributed to 3433 homes (some homes inadvertently received more than one detector during the course of the program) in the target area during the month of May. Ninety three per cent of all participants (households receiving smoke detectors) resided in single family dwellings, $2 \%$ in duplexes, $2 \%$ in garage apartments, $2 \%$ in mobile homes, and $<1 \%$ in other types of dwellings. Over 1/4 (29\%) of the participants reported children younger than 5 years of age living in the home. In addition, $24 \%$ reported persons over the age of 65 years and $12 \%$ reported physically handicapped persons in the home.

Only $228(6 \%)$ of homes requested assistance with detector installation. Those with persons over the age of 65 years $(16 \%)$ and physically handicapped (14\%) were significantly more likely to request help with installation than homes without persons over the age of $65(7 \%)$ or physical handicap $(9 \%)$ ( $<<$ $0.0001)$. Conversely, homes with children less than 5 years of age were less likely to request installation $(8 \%)$ than homes without children under the age of 5 years $(10 \%)$. Sixty eight per cent of persons who received a detector at a fire station, owned their home. This compares with $54 \%$ of persons who received a detector by the canvass method.

Fifty six per cent (2017) of the detectors were distributed in the canvassing method zip code area, even though this zip code area accounted for only $17 \%$ of all homes in the target area. The canvassing method resulted in significantly more detectors distributed to all homes in the area (31\%) compared with 5\% in the other areas $(p<0.00001)$. Using the canvassing method, detectors were also distributed to significantly more $(107 \%)$ of the homes estimated in need of one (table 1) compared with distribution to the combined number of estimated homes without detectors $(18 \%)$ in the areas which required residents to go to fire stations to receive a detector $(p<0.00001)$.

Additionally, the canvassing method distributed nearly twice as many detectors (5.9) per volunteer hour as the distribution method using fire stations (3.1). The estimated solicitation and distribution cost per detector distributed was lower for the canvassing method than for the other three methods (table 1). Following this assessment, the other three zip codes in the target area were canvassed between June and November 1990, and 6229 additional detectors were distributed to 5676 homes. In total, 9291 homes received 10100 detectors. ${ }^{14}$

\section{Discussion}

It has been estimated that $80 \%$ of fire related deaths occur in homes without working smoke detectors. ${ }^{5}$ Young children, the elderly, and persons in lower socioeconomic status neighborhoods are at the highest risk of dying in a 
residential fire. ${ }^{6122}$ Substandard housing and hazardous heating or lighting systems may be associated with lower socioeconomic status ${ }^{6}{ }^{23}$ and these high risk persons may be the least likely to purchase and maintain a smoke detector. $^{2425}$ Because smoke inhalation, not flame, is the cause of most deaths from residential fires, part of the decrease in residential fire deaths in the US may be attributable to increased use of smoke detectors since the mid-1970s. ${ }^{26}$ Smoke detectors are a reliable, inexpensive means of providing early warning of fire. ${ }^{827-29}$ The National Fire Protection Association estimated that $93 \%$ of US homes have smoke detectors; however, as many as $1 / 4$ to $1 / 3$ of US homes may have non-functioning smoke detectors. ${ }^{24} 3031 \mathrm{Com}$ paratively, the estimated detector usage in the UK has increased from $60 \%$ in 1993 to over $70 \%$ in $1995,,^{32}$ and $76 \%$ of Sweden's homes had detectors in $1992 .{ }^{4}$

This study demonstrates the effectiveness of a smoke detector giveaway among a high risk, socioeconomically disadvantaged urban population. ${ }^{14}$ We believe that the canvassing method is applicable to other urban areas and should be tested in rural settings in the US and other countries. Canvassing takes the program directly to the homes, whether apartment complexes, neighborhoods, or row homes. The area canvassed was a targeted, high risk area determined by surveillance data. Therefore, resources were concentrated in the area of greatest need, instead of being spread over the entire population and diminishing the effectiveness and efficiency of the program.

Existing residential fire related cause and prevention educational materials emphasize smoking and heating devices as the leading causes of burn injury and death. Through analysis of surveillance data, it was determined that fireplay accounted for nearly half of the residential fire related burns in the target area. Thus, educational materials that highlighted fireplay were used during the distribution. Success of prevention programs are, in part, likely depend on knowing where the injuries occur, the specific causes of those injuries, and the population characteristics of the geographically defined target area. ${ }^{33}$

The follow up survey found that $65 \%$ of the detectors were installed and working at three months ${ }^{14}$; this compares with $81 \%$ of installed functional detectors distributed in a Baltimore City study ${ }^{16}$ and $56 \%$ in a Dallas study. ${ }^{34}$ It is likely that education regarding proper installation and maintenance, as well as emergency response procedures (911), and planned and practiced escape routes accompanying the distribution of smoke detectors, increases program success. ${ }^{714} 163334$

Of the homes in the canvassing area that participated in the telephone survey, $72 \%$ reported having a functioning smoke detector, and detectors were distributed to over $100 \%$ of the estimated homes in need. It is possible that some of the participants in the canvassing program reported that they had no functioning smoke detector, but, in fact, did; it is also likely that the telephone survey overestimated the prevalence of smoke detectors. The telephone prevalence survey did not adjust for homes without telephones; $30 \%$ of the applications from the canvassing area did not report a home telephone number. During the canvass, residents were urged to check their detectors while volunteers were available to replace batteries or detectors. Many residents who thought they had working detectors (thus, would have responded affirmatively on the telephone survey) found that their detectors were not working and received new detectors through the canvass. The actual prevalence of working detectors is probably between the percentages reported by the population based telephone survey $(72 \%)$ and the fire department's data of homes that experienced a fire (23\%).

Conventional fire safety education or smoke detector distribution programs are often not successful in reaching the hard-to-reach population. $^{33} 35$ We used a community based prevention strategy that emphasized the public health approach, including coalition building. Coalitions provide community ties to gain community-wide support, decrease turf issues, expand the focus of programs, and provide the means necessary to implement a large, urban community smoke detector program. ${ }^{27} 3335$ Community groups and organizations, which already served the target area population, were a part of the coalition. They brought with them an understanding of groups in the community (Hispanic neighborhoods) and means for reaching them. ${ }^{27}{ }^{33}{ }^{35}$ Other coalition members brought with them resources (such as manpower, equipment, and materials), credibility, and expertise. Without the coalition members and their resources (time, people, money, and effort), such a large project would not have been possible.

The presence of the fire engines and Red Cross vehicles were essential in attracting attention and establishing validity and recognition in the neighborhoods. Researchers in Alaska reported that the use of many community organizations and local fire departments also lowers costs and increases program acceptance. ${ }^{17}$ Even though it was the most efficient method, canvassing a densely populated urban community requires major volunteer commitments. Even though canvassing was the least expensive distribution method, the cost was further minimized by using volunteers instead of paid laborers.

\section{Implications for prevention}

The results show that, in this urban community, direct community dissemination of detectors through neighborhood canvassing was more effective than the distribution of flyers (to every household) announcing free smoke detectors at fire stations. Canvassing also proved to be the most efficient method of distribution. The canvass method allows for multiple avenues of engagement. It draws people out of their homes, provides for interaction, and allows for the teaching of adults (information and education dissemination, demonstration, and hands-on practice). It also takes 
the program to those who do not have detectors and to those who would not normally respond to another method, and does not wait for them to come to the program. We believe that canvassing is an effective and efficient method of distributing smoke detectors in communities throughout the US and other countries.

Special thanks to former Chief Tom Smith and Assistant Chief Jon Hansen, Oklahoma City Fire Department; David Hackett, formerly with Disaster Services, Oklahoma County Chapter of the American Red Cross; registered sanitarians, City County Health Department of Oklahoma County; volunteers from the Oklahoma State Department of Health; and all the volunteers and firefighters without whose efforts this program could not have been accomplished. Special acknowledgment and gratihave been to Sandy Kuper for data entry, filing, and orga tude goes to Sandy Kuper for data entry, filing, and organization of all data relating to this project. This project was funded in part from a research grant (R49/CCR603696) from the Disease Control and Prevention.

1 Hall JR. Fire in the USA and Canada, international fire comparison report. Quincy, MA: National Fire Protection comparison report.

2 Hall JR. Fire in the USA and Fapan, international fire comparison report. Quincy, MA: National Fire Protection Association, 1994.

3 Hall JR. Fire in the USA and UK, international fire comparison report. Quincy, MA: National Fire Protection Association, 1995.

4 Hall JR. Fire in the USA and Sweden, international fire comparison report. Quincy, MA: National Fire Protection Association, 1996.

5 US Fire Administration. Fire in the United States 1983-1990. 8th Ed. Emmitsburg, MD: US Fire Administration, 1993.

6 Baker SP, O'Neill B, Ginsburg MJ, et al. The injury fact book. 2nd Ed. New York: Oxford University Press, 1992:161-73.

7 Reidinger KS. Smoke detectors: reducing deaths and injuries due to fire. Pediatrics 1980;65:718-24.

8 Karter MJ. Fire loss in the United States in 1993. National Fire Protection Association fournal 1994;88:57-65.

Fire Protection Association fournal 1994;88:57-65.
Gormsen H, Jeppesen N, Lund A. The causes of death in fire victims. Forensic Sci Int 1984;24:107-11.

10 Cohen MA, Guzzardi LJ. Inhalation of products of combustion. Ann Emerg Med 1983;12:628-32.

11 Lowry WR, Peterson J, Petty C, et al. Free radical production from controlled low-energy fires: toxicity considerations. F Forensic Sci 1985;30:73-8

12 Smith L. National estimates of US residential fire-related injuries: an improved system. Fournal of Safety Research 1994;25:221-7.

13 Levine MS, Radford MS. Fire victims: medical outcomes and demographic characteristic. Am $\mathcal{f}$ Public Health 1977;67:1077-80

14 Mallonee S, Istre G, Rosenberg M, et al. Surveillance and prevention of residential-fire injuries. $N \mathrm{Engl} f \mathrm{Med}$ 1996;335:27-31.
15 Shaw KN, McCormick MC, Kustra SL, et al. Correlates of participants in a smoke detector give-away program. $A m \mathcal{F}$ participants in a smoke detector
Public Health 1988;78:650-3.

16 Gorman RL, Charney E, Holtzman NA, et al. A successful city-wide smoke detector giveaway program. Pediatrics 1985;75:14-18.

17 Newsad RS, Mattson MH, Knapp N. Comparison of various smoke detector distribution methods. Southeast Alaska: Department of Health and Human Services, Indian Health Service (in-house publication), 1989.

18 Oklahoma State Department of Health. Oklahoma behavioral risk factor surveillance system questionnaire. Oklahoma: Oklahoma State Department of Health, 1990.

19 Dean AG, Dean JA, Coulombier D, et al. Epi-Info, version 6: a word processing, database, and statistics program for epidemiology on microcomputers. Atlanta, GA: Centers for Disease Control and Prevention, 1994.

20 Mehta CR, Patel NR, Gray R. Computing an exact confidence interval for the common odds ratio in several 2 X 2 contingency tables. 7 Am Stat Assoc 1985;80:969-73.

21 Karter MJ. Patterns of fire deaths among the elderly and children in the home. Fire fournal 1986;80(March/April): 19-22.

22 Anonymous. Deaths resulting from residential firesUnited States, 1991. MMWR Morb Mortal Wkly Rep 1994; 43(49): $901-4$

23 Runyan CW, Bangdiwala SI, Linzer MA, et al. Risk factors for fatal residential fires. N Engl f Med 1992;327:859-63.

24 Hall JR. The US experience with smoke detectors. National Fire Protection Association fournal 1994;Sept/Oct:36-46.

25 Fahy RF, Norton AL. How being poor affects fire risks. Fire fournal 1989;83(Jan/Feb):28-36.

26 Hall JR. A decade of detectors: measuring the effect. Fire fournal $1985 ; 78$ (Nov/Dec):37-43.

27 The National Committee for Injury Prevention and Control. Injury prevention: meeting the challenge. New York: Education Development, Oxford Press, 1989.

28 Hawkins RE. An evaluation of residential smoke detectors under actual field conditions: final report. Washington, DC: International Association of Fire Chiefs Foundation, March 1983.

29 Derry L. Fatal fires in America: how they happen, where they happen, how to stop them. Fire fournal 1979;73(Sept/ Oct):67-79.

30 Smith C. Smoke detector operability survey — report on findings. Bethesda, MD, US. Consumer Product Safety Commission, as revised, October 1994.

31 Anonymous. Prevalence of smoke detectors in private residences-DeKalb County, Georgia, 1985. MMWR Morb Mortal Wkly Rep 1986;35:445-8.

32 Goddard G. Summary fire statistics, United Kingdom, 1995. London: Home Office Bulletin, Research and Statistics Directorate, Issue 8/97.

33 Rossomando C. The community-based fire safety education handbook. Washington, DC: Rossomando and Associates, 1995

34 Jernigan W. Keeping the smoke detectors operational: the Dallas experience. Fire fournal 1987;81(Jul/Aug):57-63.

35 Kulenkamp A, Lundquist B, Schaenman P. Reaching the hard-to-reach: techniques from fire prevention programs and other disciplines. Arlington, VA: TriData Corporation, 1994. 